\title{
RADIATION INDUCED ESOPHAGEAL CANCER IN HODGKIN`S DISEASE
}

\author{
Muhammad Ali Memon and Arif Jamsheed
}

\begin{abstract}
An interesting case was found while audit / computation of previous medical record during last year at Nuclear Institute of Medical Radiotherapy Jamshoro - Pakistan. Case was a young lady who presented with upper third esophageal carcinoma some 14 years, after the patient had external beam radiotherapy by upper mantle field set up for stage I-A Hodgkin's disease. Long latent period, site of the second cancer at the most in-homogenous dose distribution during previous radiotherapy and deviation of age at presentation from standards seem the previous radiotherapy as cause of this second primary cancer. This case report will help to identify the factors I tools responsible for this deadly complication and for improvement in the management profile of such patients.
\end{abstract}

KEY WORDS: Esophageal cancer. Radiation induced cancer. Hodgkin`s Disease.

\section{INTRODUCTION}

Among the best-known and well-characterized carcinogens that are known from direct evidence to increase the risk of cancer in humans are physical agents, including ionizing radiation, ultraviolet (UV) light and the asbestos. ${ }^{1}$ Ionizing radiation, one of the causes of cancer is well documented. The first cancers that were related to radiation exposure were skin cancers detected as early as six years after the discovery of X-rays. ${ }^{2,3}$ Lot of work has been done on atomic bomb survivors in Japan which also established the ionizing radiation as a cause of different cancers. ${ }^{4-6}$ Long latency period from exposure to development of malignancy is a major characteristic of such events. ${ }^{2}$ The role of ionizing radiation in the management of most of cancers is also an established fact. Long term survivals are now possible due to awareness and improvement in the technology and management protocols of radiotherapy. It is now possible to document the chronic squeals of radiotherapy. Second primary cancers now comprise the leading cause of death among 15 year survivors of lymphoma. In contrast to prior surveys of adult Hodgkin's disease patients, there is significantly elevated risk of esophageal cancer. This observation complements the significant 31 to 169 fold increased risk of esophageal cancer previously noted in paediatric and young adult Hodgkin's disease populations. ${ }^{3}$ Radiation induced esophageal tumors account for less than $1 \%$ of all carcinomas of esophagus. This is a case report of a patient with carcinoma upper third esophagus. The patient had radiotherapy for Hodgkin's disease 14 years earlier by upper mantle fields. This case report will help to identify the factors / tools responsible for this deadly complication as well as for improvement in the management profile.

\section{CASE REPORT}

An interesting case of multiple primary cancers was found during audit / computation of previous medical record during last year at Nuclear Institute of Medical Radiotherapy (NIMRA) Jamshoro - Pakistan. The patient was a young female of 18 years age, who presented in July 1980 with cervical lymphadenopathy for two months without any other symptom. Excision gland biopsy reported as Hodgkin's disease. Clinical workup of the patient included chest X-ray PA view, ultrasonography of abdomen and pelvis, staging laparotomy, bone marrow examination, blood counts, liver function tests, blood urea and creatinine. All were within normal limits. Finally, patient was staged as having I-a Hodgkin's disease. The patient underwent external beam radiotherapy on a Co-60 tele-therapy unit by upper mantle field setting with mid plane dose of $45.88 \mathrm{~Gy}$ in 31 treatments over seven weeks from August 18, 1980 to October 11, 1980. One field was treated on alternate day at 2 Gy as given dose per treatment (1.48 $\mathrm{Gy}$ at $7.5 \mathrm{~cm}$ i.e. at mid plane). The 
SSD was $100 \mathrm{~cm}$ and field sizes were $33 \times 33 \mathrm{cms}$ each. Lead blocks for lungs and trachea were used to protect lungs and trachea (Figures I-III). Tissue compensators for body in - homogeneity, for proper dose distribution were not corrected in manual treatment planning. The patient remained disease free for a period of three years when she had a relapse in neck and abdominal glands with B symptoms of fever. She was kept on combination chemotherapy and received six cycles of combination chemotherapy with COPP protocol in 1983. Complete response was maintained until July 1994 (14 years after first primary diagnosis) when the patient developed dysphagia. X-ray barium swallow (Figure IV) and endoscopic biopsy were done. Finally, patient was diagnosed as squamous cell carcinoma esophagus at $20 \mathrm{cms}$ from incisors. Being unsuitable for surgery / radical radiotherapy, the patient was given two cycles of combination chemotherapy with cisplatinum and 5 flouro-uracil followed by palliative radiotherapy. Patient shown no response and subsequently expired due to progressive disease in February 1995.

FIGURE I A:

UPPER MANTLE FIELD SETTING TO TREAT HODGKIN'S DISEASE (1980)

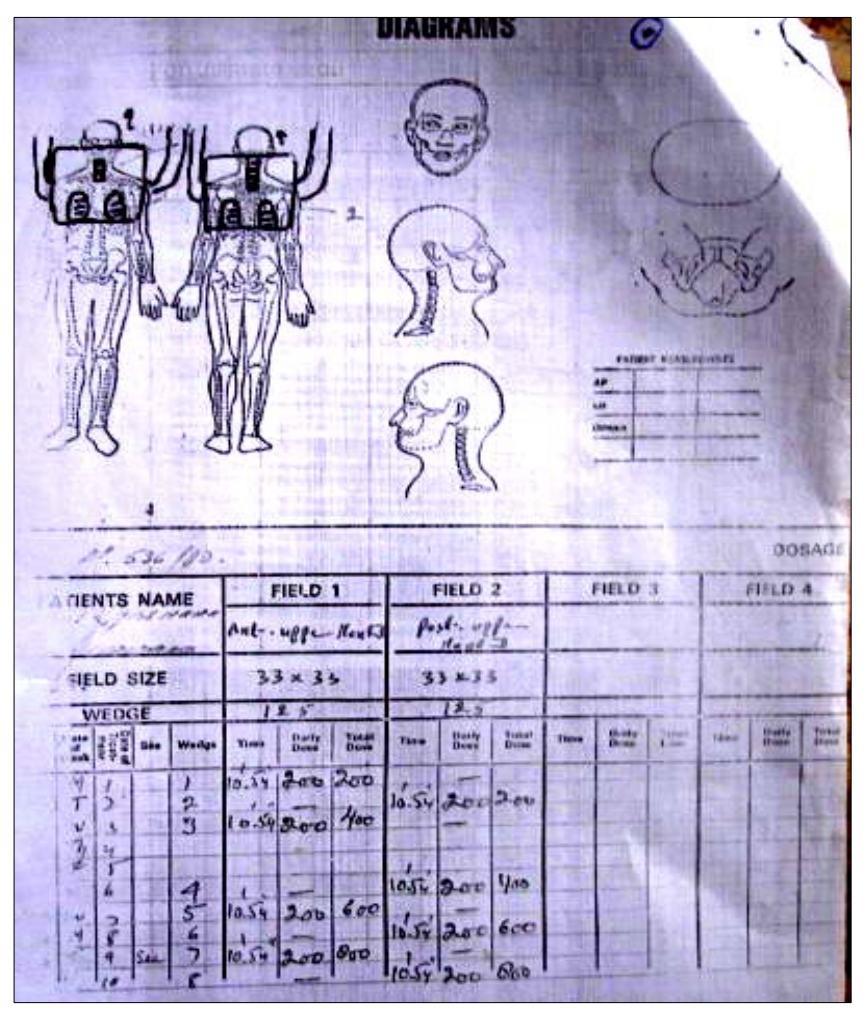

FIGURE I B:

UPPER MANTLE FIELD SETTING TO TREAT HODGKIN'S DISEASE (1980)

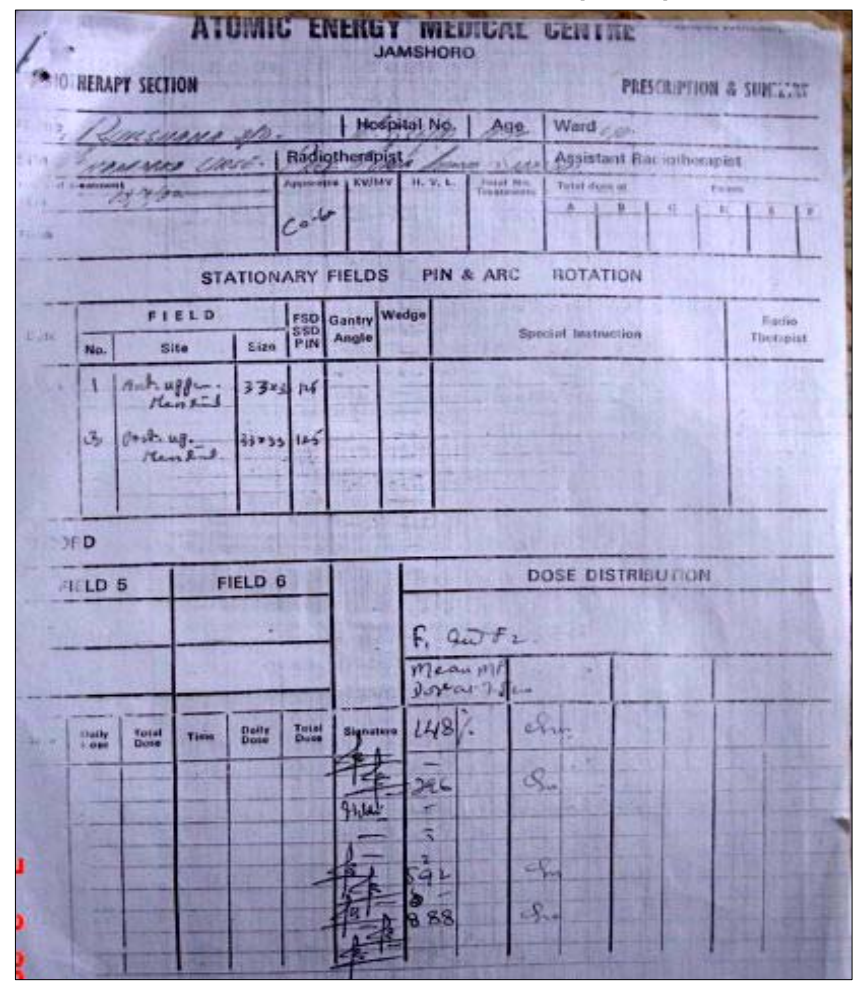

FIGURE II A:

\section{UPPER MANTLE FIELD SETTING TO TREAT HODGKIN'S DISEASE (1980)}

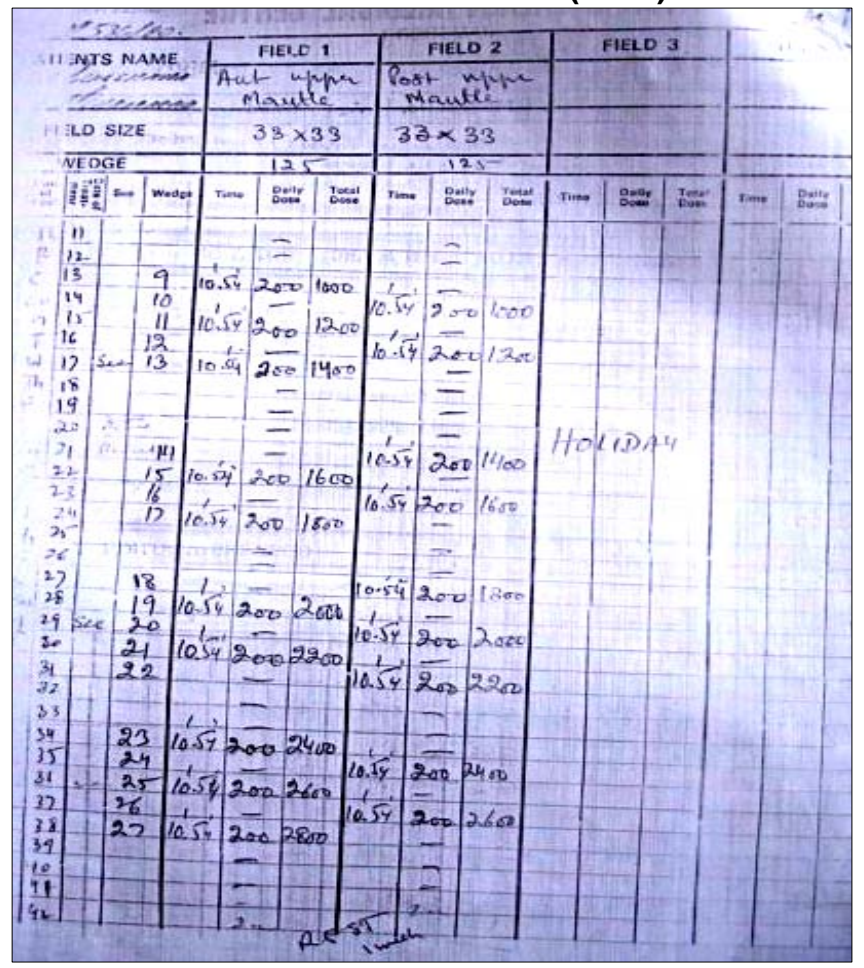




\section{FIGURE II B:}

UPPER MANTLE FIELD SETTING TO TREAT HODGKIN'S DISEASE (1980)

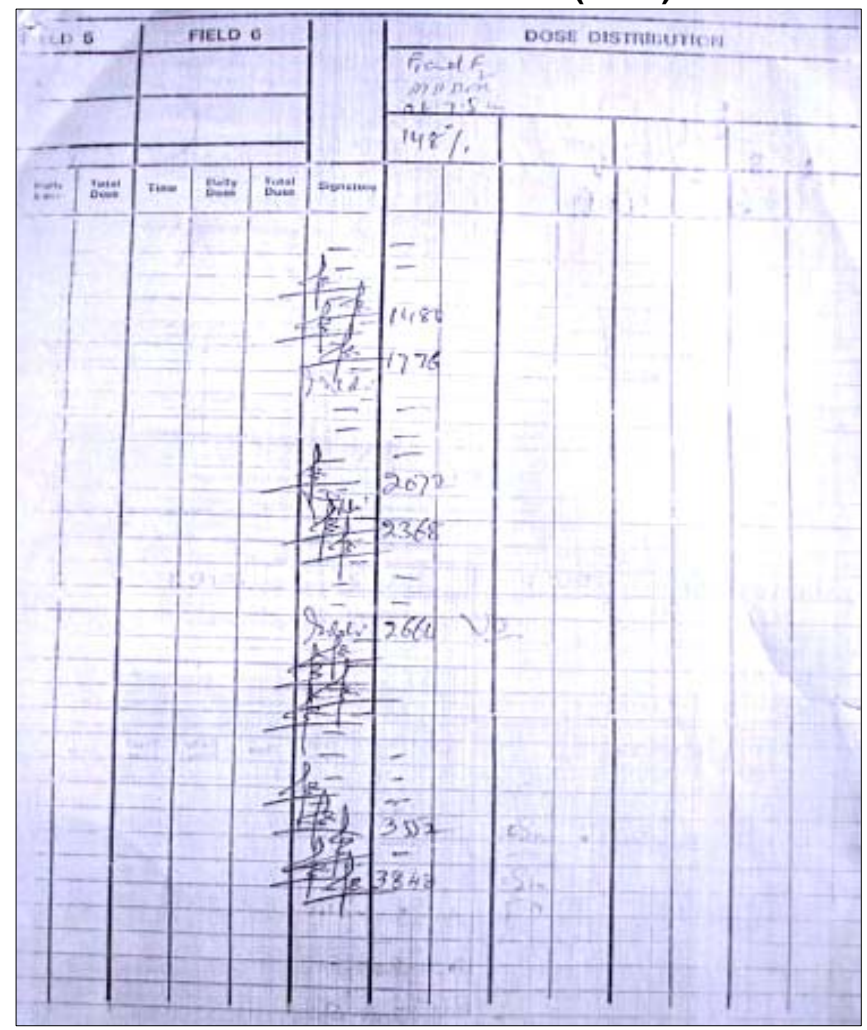

FIGURE III A:

UPPER MANTLE FIELD SETTING TO TREAT HODGKIN'S DISEASE (1980)
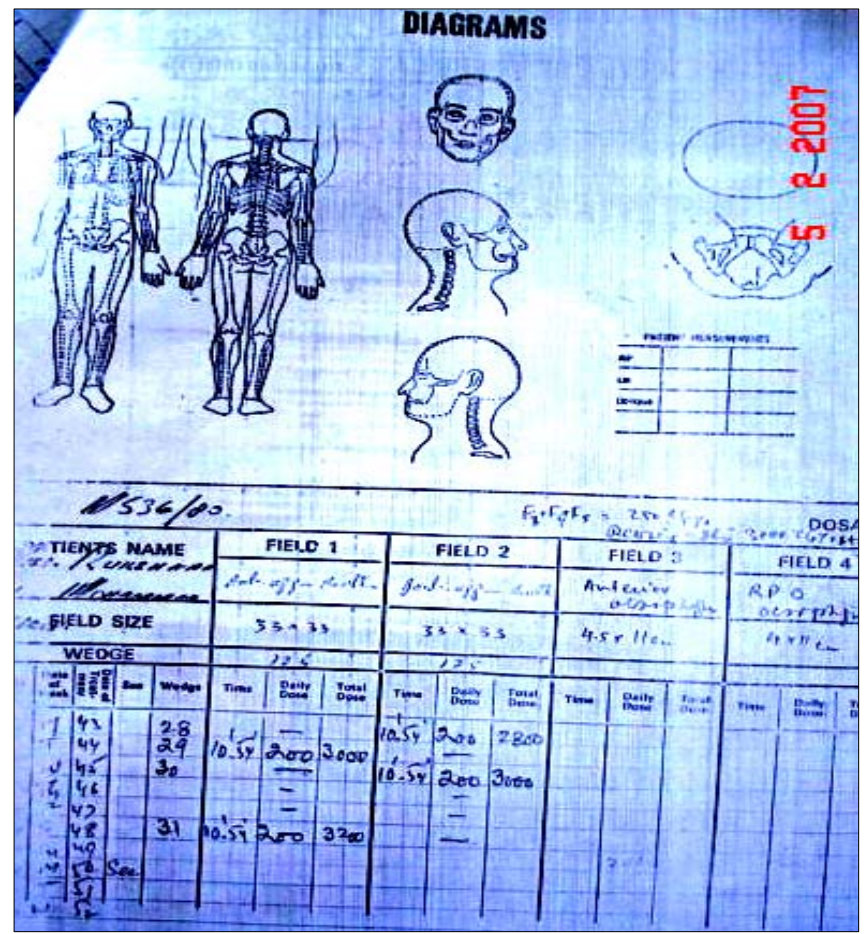

FIGURE III B:

UPPER MANTLE FIELD SETTING TO TREAT HODGKIN'S DISEASE (1980)

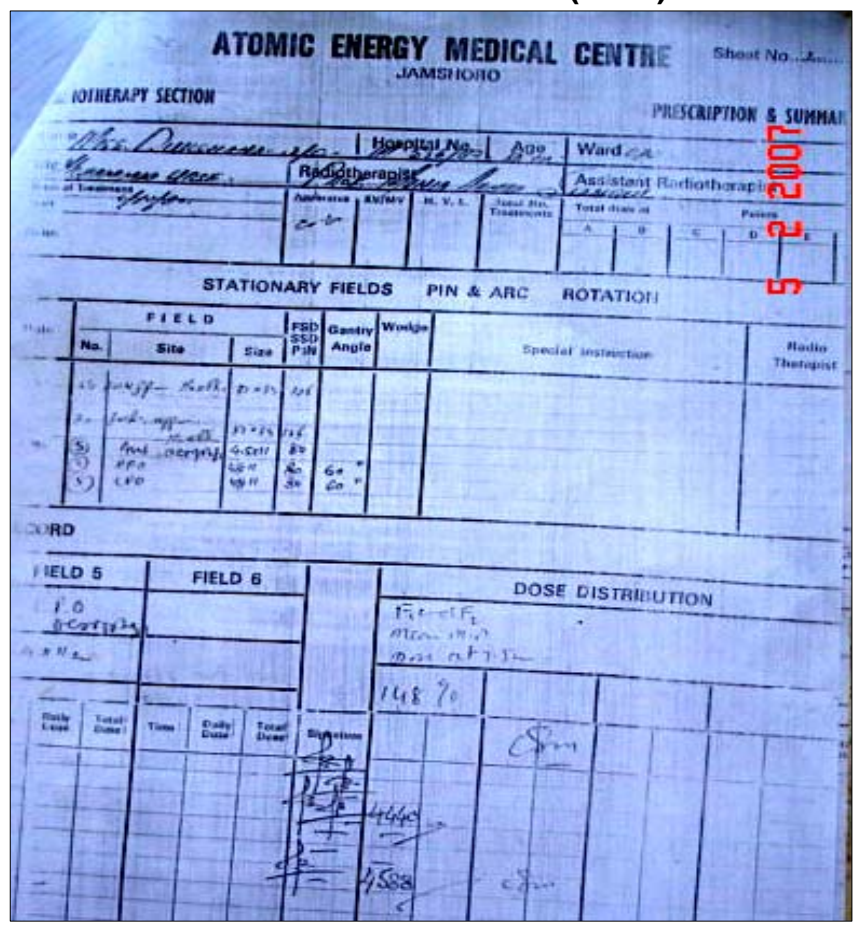

FIGURE IV:

RAT TAIL APPEARANCE AT THE LEVEL OF DORSAL VERTEBRAL SEGMENTS 3 AND 4 (1994)

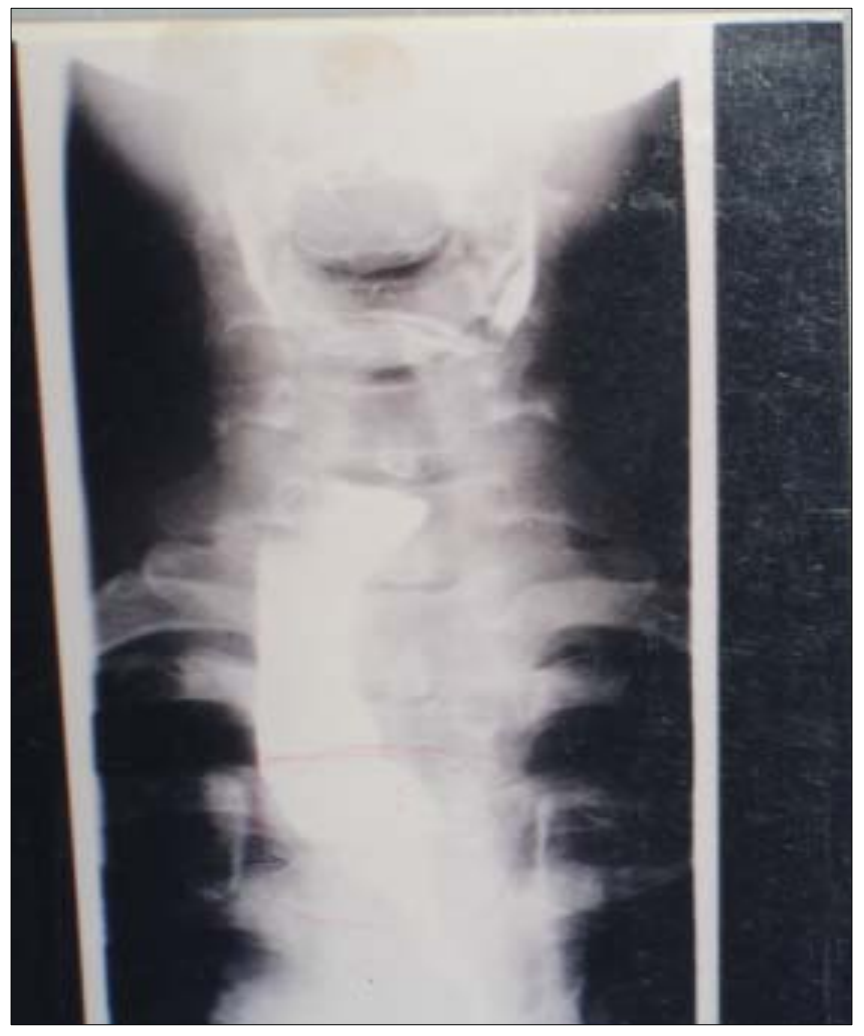




\section{DISCUSSION}

Effects of ionizing radiation are being extensively explored. The late effects of ionizing radiation have already been studied extensively in atomic bomb survivors. In medicine, ionizing radiation has a unique diagnostic and therapeutic role with narrow therapeutic index. With the improvement in the therapeutic efficacy and effective treatment protocols, long term survivals are possible. Late sequels of radiotherapy can be studied to identify the responsible factors. Considering the case under discussion, the patient presented with esophageal cancer at the age of 32 years contrary to the standard median age of 55- 60 years suggesting an unusual disease pattern i.e. late effects of previous irradiation. ${ }^{7}$ X-ray barium swallow suggested kinking of esophagus, probably due to fibrosis of previous radiation insult. Site of lesion was the area of most in-homogenous dose distribution during previous irradiation. Tissue in-homogeneity was not corrected. Simulator was not available at the time of previous radiotherapy for Hodgkin's disease, so field matching was not appropriate. Dose distribution was not homogenous throughout treatment fields. Theoretically, a contribution of $50 \%$ of delivered dose at the margins of blocks also adds to the in-homogeneity of dose distribution. Total time and fraction scheme was not according to linear quadratic model i.e. $45.88 \mathrm{~Gy}$ at mid plane in 31 treatments over seven weeks from August 18, 1980 to October 11, 1980. One field was treated on alternate day at 2 Gy as given dose per treatment (1.48 Gy at $7.5 \mathrm{~cm}$ i.e. mid plane). It is presumed that the overall treatment time and schedule for inhomogenously exposed sub-lethally damaged tissues have sufficient recovery time for abnormal repair that might expressed as subsequent second pathology. ${ }^{8}$ This case report is unique as it guides clinicians to improve treatment planning, to update equipments and expertise according to fast growing medical science. Total dose, fractionation scheme, total treatment time, multiple field matching, use of proper tissue compensators / blocks, proper selection of beam / beam energy, correction for irregular patients contour and inter / intra treatment movements, normal tissue tolerance, patients general condition as well as under- lying primary and concurrent disease should all be considered for proper execution of radiotherapy to get best results in the management of different cancers.

\section{REFERENCES}

1. Ullrich LR. Etiology of cancer: physical factors. In Vincent T. Devita Jr. Principles \& Practice of Oncology. $7^{\text {th }}$ ed. Philadelphia: Lippincott Williams \& Walkins. 2005; Chapter 10.

2. Miller RW. Delayed effects of external radiation exposure: a brief history. Radiat Res.1995; 144 (2):160-9.

3. Shore RE. Radiation-induced skin cancer in humans. Med Pediatr Oncol. 2001; 36(5):549-54. Review

4. UNSCEAR. Sources and effects of ionizing radiation. New York: United Nations, 2000.

5. Preston DL, Shimizu Y, Pierce DA, Suyama A, Mabuchi K. Studies of mortality of atomic bomb survivors. Report 13: Solid cancer and non-cancer disease mortality: 1950-1997. Radiat Res. 2003; 160(4): 381-407.

6. Brenner DJ, Doll R, Goodhead DT, Hall EJ,Land $\mathrm{CE}$, Little JB, et al. Cancer risks attributable to low doses of ionizing radiation: assessing what we really know? Proc Natl Acad Sci USA. 2003; 100 (24): 13761- 6.

7. Dores GM, Metayer C, Curtis RE, Lynch CF, Clarke EA, Glimelius B, et al. Second malignant neoplasms among long-term survivors of Hodgkin's disease: A population-based evaluation over 25 years. J Clin Oncol. 2002; 20(16): 3484-94.

8. Micke O, Schafer U, Glashorster M, Prott FJ, Villich N. Radiation-induced esophageal carcinoma 30 years after mediastinal irradiation: case report and review of the literature. Jpn J Clin Oncol. 1999; 29(3):164-70. Review.

\section{ACKNOWLEDGMENTS}

Authors are grateful to Dr. Akhtar Ahmad, Dr. Rukhsana Memon and Dr. Aisha Siddiqua of Nuclear Institute of Medical Radiotherapy, Jamshoro for their contribution in the write up of this manuscript.

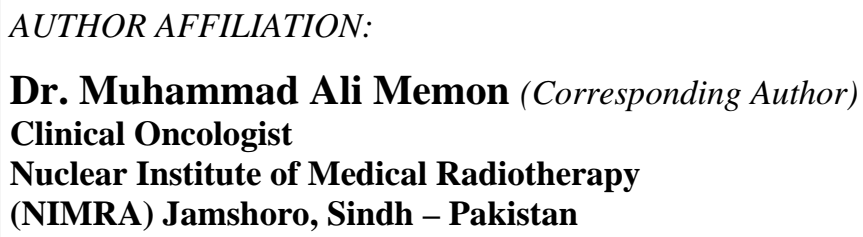

\author{
Dr. Arif Jamsheed \\ Consultant Oncologist \\ Shaukat Khanum Cancer Hospital \& Research Centre \\ Lahore - Pakistan
}

